\title{
Desempenho germinativo de sementes de soja revestidas com polímeros hidrofílicos
}

\author{
Marina Scarsi, Jean Carlo Possenti, Renata Paula Herrera Brandelero, Cristiane Deuner* \\ Universidade Tecnológica Federal do Paraná - UTFPR, PR. *E-mail: cdeuner@yahoo.com.br
}

\section{Resumo}

O uso de polímeros biodegradáveis e biocompatíveis no revestimento de sementes tem se tornado importante devido às suas propriedades biológicas desejáveis e renováveis. O presente estudo teve como objetivo avaliar o efeito de polímeros hidrofílicos sobre o processo de absorção de água e atributos fisiológicos de sementes de soja, cultivar NK 7059 RR. As sementes foram submetidas ao revestimento com os polímeros amido de mandioca, alginato de sódio e álcool polivinílico em quatro concentrações, sendo 0 , 2, 4 e $6 \%$. A absorção de água foi avaliada em intervalos de três horas durante 24 horas, totalizando oito avaliações. Para a qualidade fisiológica as sementes foram submetidas aos testes de primeira contagem de germinação, germinação, índice de velocidade de germinação, envelhecimento acelerado, emergência em casa de vegetação, índice de velocidade de emergência e condutividade elétrica. Os polímeros utilizados no presente estudo aumentam o percentual de absorção de água das sementes, principalmente o alginato de sódio na concentração de $4 \%$. O revestimento com alginato de sódio afeta a qualidade fisiológica das sementes. $O$ aumento na concentração dos polímeros afeta negativamente a emergência das plântulas, e no caso do alginato de sódio reduz a germinação e o vigor das sementes.

Palavras chave: Glycine max; recobrimento; qualidade fisiológica.

\section{Germinative performance of soybean seeds coated with hidrophyl polymers}

\begin{abstract}
Abstrac
The use of biodegradable and biocompatible polymers in seeds coated has become important due to their desirable and renewable biological properties. The present study aimed to evaluate the effect of hydrophilic polymers on the water absorption process and physiological attributes of soybean seeds, NK 7059 RR cultivar. The seeds were coated with cassava starch, sodium alginate and polyvinyl alcohol biopolymers at four different concentrations $0,2,4$ and $6 \%$. The water absorption process was evaluated at three hour intervals for 24 hours, totaling eight evaluations. For physiological quality the seeds were submitted to the tests of first germination count, germination, germination speed index, accelerated aging, greenhouse emergence, emergence speed index and electrical conductivity. The polymers used in the present study increase the percentage of seed soaking, especially sodium alginate at a concentration of $4 \%$. The increase in the concentration of polymers negatively affects seedling emergence, and in the case of sodium alginate it reduces germination and seeds vigor.
\end{abstract}

Keywords: Glycine max; coating; physiological quality.

\section{Introdução}

Utilizar sementes de qualidade e empregar produtos que possibilitem melhoria do desempenho destas no campo são elementos importantes para uma alta produção agrícola (LUDWIG et al., 2011). Uma das formas de adicionar produtos às sementes é através do recobrimento, em que é aplicada camada fina e uniforme de polímero à superfície da semente, em quantidades precisas contribuindo para a redução de impacto ambiental (BAUDET; PERES, 2004).

Segundo Benatto Junior et al. (2012), o revestimento das sementes com polímeros é 
capaz de proporcionar melhorias significativas nas condições de semeadura, reduz perdas de agroquímicos causados pelo atrito entre semente e semeadora e, também, causa menor risco na manipulação desses materiais pelos operadores. Por outro lado, é importante que os filmes poliméricos não afetem negativamente 0 processo de germinação e o vigor das sementes (OLIVEIRA et al., 2009).

Além disso, cada vez mais se intensifica a busca por produtos naturais com propriedades poliméricas que possam contribuir para a sustentabilidade e que não causem impacto negativo ao meio ambiente (FARIAS et al., 2016). Os materiais obtidos de fontes renováveis possuem um ciclo de vida curto comparado aos materiais de fontes fósseis como o petróleo, os quais levam milhares de anos para se formar. Dessa forma, em função de fatores ambientais e sócio-econômicos tem sido crescente o interesse pelos biopolímeros (BRITO et al., 2011), ou seja, polímeros ou copolímeros produzidos a partir de matérias-primas de fontes renováveis, provenientes de animais ou plantas. Esses possuem um ciclo de vida mais curto comparado às fontes fósseis e são bastante convenientes como matéria prima para uma produção mais ecologicamente atrativa (BRITO et al., 2011; REDDY et al., 2013).

Os polímeros, sejam naturais ou sintéticos, são classificados em hidrofílicos ou hidrofóbicos, sendo que os materiais hidrofílicos atraem água quando secos e os hidrofóbicos a repelem quando molhados (BENATTO JUNIOR et al., 2012). A utilização de cada um depende das características do ambiente e o resultado desejado com a utilização dos mesmos. Entretanto, independente do tipo, o polímero ideal deve ser obrigatoriamente solúvel em água e permitir a embebição ou absorção de água pelas sementes (WEST, 1983), oferecendo as condições necessárias para a germinação.

O álcool polivinílico é um polímero biodegradável obtido pela remoção dos grupos acetatos do polivinilacetato, resultando em um polímero parcial ou completamente substituído (BRANDELERO et al., 2015). Já polímeros naturais, como os de alginato e de amido são hidrofílicos, provenientes de recursos renováveis, de alta disponibilidade e baixo custo. Características como a ação gelificante e espessante, biodegradabilidade, biocompatibilidade e ausência de toxidez tornam o alginato de sódio um material interessante para inúmeras aplicações. Porém, em função da sua natureza hidrofílica, o alginato exibe baixa resistência à água, limitando, em muitos casos, sua aplicabilidade (LIMA et al., 2007). O amido é a maior reserva de carboidratos em plantas e é certamente um dos materiais mais versáteis para uso potencial em polímeros (BRITO et al., 2011).

A importância de polímeros sintéticos biodegradáveis, biocompatíveis, tais como o álcool polivinílico (PVA), polímeros naturais como alginato, amido e outros cresceu significativamente durante as duas últimas décadas, devido às suas propriedades biológicas desejáveis e renováveis. Porém, dentre os três o álcool polivinílico não é muito elástico e tem limitada hidrofilicidade (KAMOUN et al., 2015). Nesse sentido, o objetivo com o presente estudo foi avaliar o efeito de polímeros no processo de absorção de água e sobre os atributos fisiológicos de sementes de soja.

\section{Material e Métodos}

O trabalho foi desenvolvido nos laboratórios de análises de sementes dos Câmpus de Pato Branco e de Dois Vizinhos e na estufa experimental do Câmpus Pato Branco da Universidade Tecnológica Federal do Paraná UTFPR. Utilizaram-se sementes de soja da cultivar NK 7059 RR, classe S1, peneira 6,5 mm. Os polímeros utilizados para o recobrimento das sementes foram amido de mandioca (AM), alginato de sódio (ALG) de viscosidade média, e álcool polivinílico ( $\mathrm{PVOH}$ ) com $99 \%$ de grau de hidrólise e peso molar $89.000-98.000 \mathrm{~mol} \mathrm{~L}^{-1}$.

Inicialmente as sementes foram submetidas a testes para caracterização do lote utilizado, sendo realizado o peso de mil sementes e determinado o grau de umidade, de acordo com as Regras para Análise de Sementes - RAS (BRASIL, 2009). Também foi realizado o teste de tetrazólio segundo metodologia descrita por França Neto et al. (1998).

Em seguida foram preparadas as soluções de cada polímero de acordo com as concentrações desejadas sendo, 2, 4 e $6 \mathrm{~g}$ polímero $100 \mathrm{~mL}^{-1}$ água, além de uma testemunha (sem adição de revestimento), correspondendo portanto a 0, 2, 4 e $6 \%$. Os polímeros foram misturados em água destilada nas respectivas quantidades, de acordo com cada concentração, e em seguida aquecidos até a temperatura de gelatinização (AM: $72{ }^{\circ} \mathrm{C}$, ALG: 60 ${ }^{\circ} \mathrm{C}$; PVOH: $95{ }^{\circ} \mathrm{C}$ ), sendo mantidos sob agitação mecânica por 15 minutos. 
Após esse período as soluções foram resfriadas até temperatura ambiente (próximo a $21^{\circ} \mathrm{C}$ ), quando se adicionaram as sementes, na proporção de $500 \mathrm{~g}$ de semente para $250 \mathrm{~mL}$ de solução, permanecendo em contato com a solução durante um minuto. Depois de recobertas, as mesmas foram colocadas em uma centrífuga para retirar o excesso de solução.

As sementes foram então acondicionadas em um saco plástico juntamente com $2 \mathrm{~g}$ do pó secante Dynapro Silver, sendo esse fechado e agitado suavemente por um minuto, para o espalhamento do pó sobre o polímero. 0 pó secante foi adicionado para secar a superfície das sementes e obter uma cobertura perolada com acabamento similar às sementes comerciais.

Depois de revestidas, determinou-se a percentagem de absorção de água pelas sementes e a sua qualidade fisiológica. Para avaliar o processo de absorção de água nas sementes com polímeros foram utilizadas quatro repetições de 50 sementes, as quais foram pesadas em balança de precisão para determinação do seu peso inicial. Em seguida, envolvidas em rolo de papel umedecido, foram acondicionadas em câmara de germinação modelo Mangelsdorf a $25{ }^{\circ} \mathrm{C}$, sendo realizadas pesagens a cada três horas para a obtenção do peso final. A absorção de água foi calculada utilizando a fórmula: $\% \mathrm{~A}=[(\mathrm{PF}-\mathrm{PI}) / \mathrm{PI}] \times 100$, em que $\% \mathrm{~A}=$ porcentagem de absorção, $\mathrm{PF}=$ peso final da amostra e PI = peso inicial da amostra, e os resultados expressos em percentagem (BRASIL, 2009). As pesagens foram realizadas em intervalos de três horas, durante um período de 24 horas, totalizando oito avaliações.

A qualidade fisiológica das sementes foi avaliada pelas seguintes variáveis: Germinação e primeira contagem de germinação (BRASIL, 2009); Índice de velocidade de germinação: calculado pelo somatório do número de sementes germinadas a cada dia, dividido pelo número de dias decorridos entre a semeadura e a germinação, de acordo com a fórmula de Maguire (1962); Envelhecimento acelerado: realizado com amostras de 45 gramas de sementes alocadas em uma BOD por um período de 48 horas a $41{ }^{\circ} \mathrm{C}$, conforme metodologia de Krzyzanowski et al. (1999), sendo em seguida submetidas ao teste de germinação (BRASIL, 2009); Condutividade elétrica: realizado de acordo com metodologia descrita por Vieira e Krzyzanowski (1999), sendo a leitura em condutivímetro Gehaka CG 2000 e os resultados expressos em $\mu \mathrm{S} \mathrm{cm}^{-1} \mathrm{~g}^{-1}$ de semente. A condutividade elétrica dos polímeros foi medida em separado e diminuído esse valor do obtido da semente juntamente com o polímero para a obtenção da condutividade apenas das sementes. Após a medição, os resultados foram analisados conjuntamente através de regressão para ajuste dos valores de condutividade elétrica (VIEIRA et al., 2002), conforme a equação: $\mathrm{CE}=[0,3227+$ $0,05115(T A)] \times$ CEo, onde CE é a condutividade elétrica corrigida ( $\mu \mathrm{S} \mathrm{cm}^{-1} \mathrm{~g}^{-1}$ ), TA é o teor de água observado nas sementes (\%), CEo é a condutividade elétrica observada $\left(\mu \mathrm{S} \mathrm{cm}^{-1} \mathrm{~g}^{-1}\right)$; Emergência em casa de vegetação: realizada em canteiros de casa de vegetação experimental contendo latossolo vermelho aluminoférrico com textura argilosa, segundo o Sistema Brasileiro de Classificação de Solos (EMBRAPA, 2018). A semeadura foi feita manualmente a uma profundidade de três centímetros, em quatro linhas com 100 sementes em cada. A contagem foi realizada até a estabilização do estande de plantas, que se deu com quinze dias de semeadura; Índice de velocidade de emergência (IVE): determinado a partir das plântulas da emergência em casa de vegetação, sendo efetuado pela contagem diária de plântulas emergidas até que o número estabilizasse. O IVE foi calculado utilizando-se o método descrito por Maguire (1962).

O delineamento experimental utilizado foi o inteiramente casualizado, com quatro repetições. O modelo estatístico adotado foi bifatorial, sendo que o fator A constituiu-se dos três polímeros estudados (AM, ALG e PVOH) e o fator $B$, as quatro concentrações $(0,2,4$ e $6 \%)$, totalizando-se 48 unidades experimentais. Para análise estatística, o conjunto de dados foi submetido ao teste de Lilliefors para verificação da normalidade dos dados, os quais foram transformados para ARCSEN $\mathrm{V}(\mathrm{x} / 100)$ antes de serem submetidos à análise da variância. Inicialmente verificou-se o nível de significância dos fatores e das suas interações, aplicando-se o Teste F. O fator A (polímeros) foi avaliado pelo teste de comparação de médias de Tukey, ao nível de $5 \%$ de probabilidade e o fator B (concentrações) foi avaliado mediante regressão polinomial. Para auxílio nas análises estatísticas, utilizou-se o programa computacional Assistat (SILVA; AZEVEDO, 2009) e para as análises de regressão o Sigmaplot 10.0 (SYSTAT SOFTWARE, 2006). 


\section{Resultados e Discussão}

Na Tabela 1 são apresentados os dados do teste de tetrazólio, peso de mil sementes e grau de umidade de acordo com a caracterização inicial do lote. Não foi observado dano por umidade e a viabilidade apresentou-se dentro do padrão exigido pelo Ministério da Agricultura, Pecuária e Abastecimento (BRASIL, 2013), que é de $80 \%$. Na porcentagem de dano mecânico observou-se alta expressividade de sementes danificadas, sendo que segundo a classificação de França Neto et al. (1998), percentuais entre 7 a $10 \%$ são considerados um problema sério. Esse percentual de dano mecânico provavelmente está associado ao grau de umidade das sementes, pois quando colhidas com umidade inferior a $12 \%$ estão vulneráveis ao dano mecânico imediato, e quando acima de $15 \%$ estão sujeitas a danos mecânicos latentes, ou seja, não perceptíveis (FRANÇA NETO; HENNING, 1984). Vale ressaltar que a caracterização inicial do lote serve como demonstrativo da qualidade que as sementes possuem, sendo importante utilizar sementes com viabilidade acima de $80 \%$, como as do presente estudo.

Tabela 1. Caracterização inicial do lote de sementes de soja pelas variáveis viabilidade (\%), vigor (\%), dano mecânico (\%), dano por umidade (\%) e dano por percevejo (\%) avaliados pelo teste de tetrazólio, e peso de mil sementes (PMS; g) e grau de umidade (\%).

\begin{tabular}{ccccccc}
\hline Viabilidade & Vigor & $\begin{array}{c}\text { Dano } \\
\text { mecânico }\end{array}$ & $\begin{array}{c}\text { Dano } \\
\text { Umidade }\end{array}$ & $\begin{array}{c}\text { Dano } \\
\text { Percevejo }\end{array}$ & PMS & $\begin{array}{c}\text { Grau } \\
\text { Umidade }\end{array}$ \\
\hline 91 & 78 & 8 & 0 & 1 & 197,2 & 9 \\
\hline
\end{tabular}

Analisando a absorção de água pelas sementes (Figura 1) verifica-se que para todos os polímeros e concentrações a curva de absorção apresentou comportamento quadrático positivo conforme aumentou do período de hidratação. Também pode-se observar que o recobrimento de sementes de soja com ALG, na concentração de $4 \%$ (Figura 1B), obteve maior absorção comparado aos demais polímeros, apresentado uma porcentagem de absorção de água superior aos demais polímeros testados e da testemunha em todos os períodos avaliados. 
Figura 1. Percentual de absorção de água de sementes de soja recobertas com diferentes polímeros (Test testemunha, AM - amido de mandioca, ALG - alginato de sódio, PVOH - álcool polivinílico) nas concentrações de 2 (A), 4 (B) e 6\% (C), em oito períodos de avaliação.
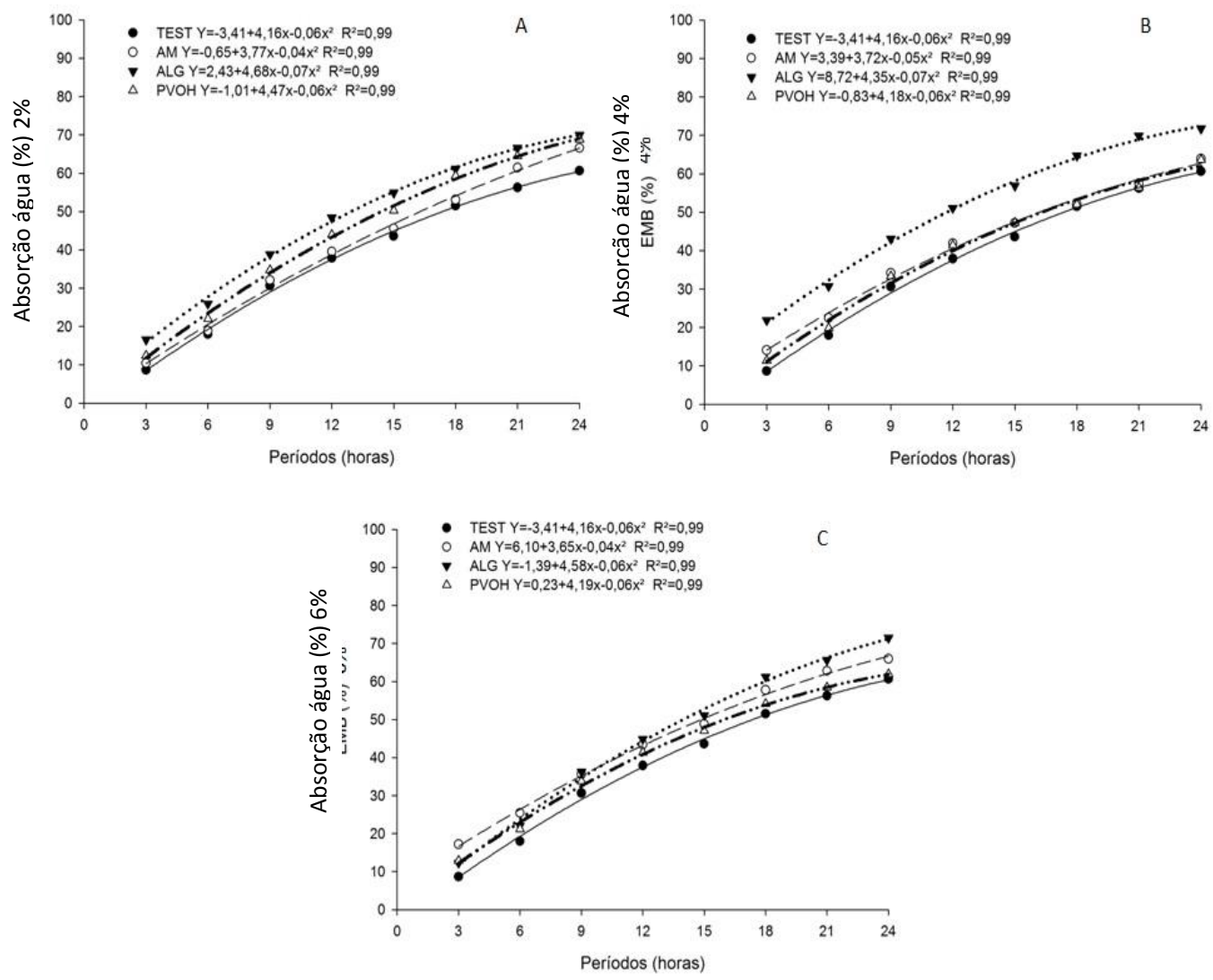

Pode observar, embora sem a barra de erro, que na concentração de $2 \%$ a testemunha apresenta menor absorção de água que os demais tratamentos após 21 e $24 \mathrm{~h}$ do início da hidratação das sementes (Figura 1A). De maneira geral, ao longo do período de hidratação, a testemunha apresentou ganhos de água inferiores aos demais tratamentos (Figura 1).

Esses dados corroboram com os resultados encontrados por Huth et al. (2013) estudando a velocidade de embebição de sementes de soja recobertas com fungicida (Derosal Plus $\left.{ }^{\circledR}\right)$, inseticida $\left(\right.$ Cropstar $\left.^{\circledR}\right)$ e polímeros (FloRite 1197 da Nitral Urbana ${ }^{\circledR}$, e Laborsan da Laborsan $^{\circledR}$ ) ambos na dose de $1 \mathrm{~mL} \mathrm{~kg}^{-1}$ de sementes. Segundo os autores, o menor teor de água apresentado pela testemunha em relação aos demais tratamentos pode ser devido à hidrofilicidade apresentada pelos princípios ativos utilizados. Dessa forma, independentemente do objetivo final da peliculização, conhecer os padrões referentes às interações entre a semente e a viscosidade, resistência e plasticidade dos materiais de recobrimento é fundamental para o sucesso de tal operação (MELO et al., 2014).

A análise de variância apontou interação significativa para as variáveis primeira contagem de germinação (PCG), germinação $(G)$, índice de velocidade de germinação (IVG), envelhecimento acelerado (EA) e condutividade elétrica (CE) das sementes de soja. A emergência em casa de vegetação $(E C V)$ e o índice de velocidade de emergência (IVE) apresentaram diferença significativa aos fatores de forma isolada (Tabela 2). 
Tabela 2. Resumo da análise de variância para os caracteres primeira contagem de germinação (PCG), germinação (G), índice de velocidade de germinação (IVG), envelhecimento acelerado (EA), emergência em casa de vegetação (ECV), índice de velocidade de emergência (IVE) e condutividade elétrica (CE) de sementes da cultivar de soja, NK 7059 RR, revestidas com três polímeros distintos - amido de mandioca $(\mathrm{AM})$, alginato de sódio (ALG) e álcool polivinílico (PVOH), em quatro concentrações diferentes - 0, 2, 4 e $6 \%$.

\begin{tabular}{ccccccccc}
\hline FV & GL & PCG & G & IVG & EA & EC & IVE & CE \\
\hline Polímero & 2 & $0,084^{*}$ & $0,185^{*}$ & $0,020^{*}$ & $0,202^{*}$ & $0,022^{*}$ & $0,001^{*}$ & 301,39 \\
Concentração & 3 & $0,155^{*}$ & $0,134^{*}$ & $0,020^{*}$ & $0,116^{*}$ & $0,073^{*}$ & $0,002^{*}$ & $9668,13^{*}$ \\
P x C & 6 & $0,030^{*}$ & $0,048^{*}$ & $0,006^{*}$ & $0,082^{*}$ & 0,003 & $2 \times 10^{-3}$ & $6238,57^{*}$ \\
CV (\%) & & 12,1 & 7,2 & 7,3 & 10,5 & 6,9 & 7,1 & 15,9 \\
\hline
\end{tabular}

* significativo ao nível de $5 \%$ de probabilidade $(p<0,05)$

Analisando os dados obtidos nas diferentes variáveis em função do polímero utilizado (Tabela 3) observa-se que, para a PCG, não houve diferença entre eles nas concentrações de 0 e $2 \%$, enquanto que em $6 \%$ o $\mathrm{PVOH}$ apresentou maior percentual de plântulas normais diferindo significativamente do ALG, que ocasionou menor número de plântulas normais. Tanto na G quanto no IVG o ALG foi inferior aos demais nas concentrações de 2, 4 e $6 \%$, porém, sem diferir significativamente do AM em $2 \%$, enquanto no teste de envelhecimento acelerado o alginato de sódio foi inferior aos outros na concentração de 4 e 6\%. Para o IVE e a ECV o ALG apresentou valores inferiores aos demais, sem diferir significativamente do PVOH. 
Tabela 3. Dados médios para a primeira contagem de germinação (PCG), germinação (G), índice de velocidade de germinação (IVG), envelhecimento acelerado (EA), índice de velocidade de emergência (IVE), emergência em casa de vegetação (ECV) e condutividade elétrica (CE) de sementes de soja revestidas com três polímeros distintos - amido de mandioca (AM), alginato de sódio (ALG) e álcool polivinílico (PVOH), em quatro concentrações.

\begin{tabular}{|c|c|c|c|c|}
\hline \multirow{3}{*}{ Concentrações } & \multicolumn{3}{|c|}{ Polímeros } & \multirow{3}{*}{ Média } \\
\hline & AM & ALG & $\mathrm{PVOH}$ & \\
\hline & \multicolumn{3}{|c|}{ PCG (\%) } & \\
\hline 0 & $66 a^{*}$ & $66 \mathrm{a}$ & $66 \mathrm{a}$ & 66 \\
\hline 2 & $57 a$ & $49 a$ & $55 \mathrm{a}$ & 54 \\
\hline 4 & $49 a b$ & $43 \mathrm{~b}$ & $55 \mathrm{a}$ & 49 \\
\hline 6 & $45 \mathrm{~b}$ & $20 c$ & $56 a$ & 40 \\
\hline Média & 77 & 35 & 81 & \\
\hline \multicolumn{5}{|c|}{ G (\%) } \\
\hline 0 & $85 \mathrm{a}$ & $85 \mathrm{a}$ & $85 \mathrm{a}$ & 85 \\
\hline 2 & $76 \mathrm{ab}$ & $69 \mathrm{~b}$ & $80 a$ & 75 \\
\hline 4 & 73 a & $57 \mathrm{~b}$ & 75 a & 68 \\
\hline 6 & $73 \mathrm{a}$ & $35 \mathrm{~b}$ & $81 \mathrm{a}$ & 63 \\
\hline Média & 77 & 62 & 80 & \\
\hline \multicolumn{5}{|c|}{ IVG } \\
\hline 0 & $21,32 \mathrm{a}$ & $21,32 \mathrm{a}$ & $21,32 \mathrm{a}$ & 21,32 \\
\hline 2 & $18,81 \mathrm{ab}$ & $16,66 \mathrm{~b}$ & 19,28 a & 18,25 \\
\hline 4 & $16,67 \mathrm{a}$ & $13,50 \mathrm{~b}$ & $18,24 \mathrm{a}$ & 16,13 \\
\hline 6 & $15,88 \mathrm{~b}$ & $7,72 \mathrm{c}$ & $19,71 \mathrm{a}$ & 14,43 \\
\hline Média & 18,17 & 14,80 & 19,63 & \\
\hline \multicolumn{5}{|c|}{ EA (\%) } \\
\hline 0 & $79 \mathrm{a}$ & $79 \mathrm{a}$ & $79 \mathrm{a}$ & 79 \\
\hline 2 & $72 \mathrm{a}$ & $67 a$ & $75 \mathrm{a}$ & 71 \\
\hline 4 & $66 \mathrm{a}$ & $53 \mathrm{~b}$ & $71 \mathrm{a}$ & 63 \\
\hline 6 & $74 \mathrm{a}$ & $23 \mathrm{~b}$ & $76 \mathrm{a}$ & 58 \\
\hline Média & 72 & 55 & 75 & \\
\hline & & IVF & & \\
\hline 0 & 10,9 & 10,9 & 10,9 & 10,9 \\
\hline 2 & 9,8 & 8,8 & 8,7 & 9,1 \\
\hline 4 & 10,0 & 8,7 & 8,7 & 9,1 \\
\hline 6 & 9,9 & 8,4 & 8,2 & 8,9 \\
\hline \multirow{2}{*}{\multicolumn{5}{|c|}{$\frac{9,17 b}{\mathrm{ECV}(\%)}$}} \\
\hline & & & & \\
\hline 0 & 84 & 84 & 84 & 84 \\
\hline 2 & 74 & 67 & 72 & 71 \\
\hline 4 & 74 & 66 & 73 & 71 \\
\hline 6 & 76 & 65 & 68 & 70 \\
\hline Média & $77 \mathrm{a}$ & $70 \mathrm{~b}$ & $74 a b$ & \\
\hline \multicolumn{5}{|c|}{$\mathrm{CE}\left(\mu \mathrm{S} \mathrm{cm} \mathrm{cm}^{-1} \mathrm{~g}^{-1}\right)$} \\
\hline 0 & 134 & 134 & 134 & 134 \\
\hline 2 & 108 & 138 & 95 & 114 \\
\hline 4 & 115 & 155 & 99 & 123 \\
\hline 6 & 112 & 5 & 100 & 71 \\
\hline Média & 115,25 & 106,75 & 107,00 & \\
\hline
\end{tabular}

*Médias seguidas pela mesma letra na linha não diferem significativamente entre si, pelo teste de Tukey ao nível de $5 \%$ de probabilidade. 
Pode-se observar que tanto para a PCG, G e IVG os tratamentos com os polímeros ALG e AM apresentaram redução linear na percentagem de plântulas normais conforme aumentou a concentração do polímero. Já o PVOH apresentou comportamento quadrático para as três variáveis (Figura 2).

Para a PCG observou-se que a testemunha apresentou percentagem superior aos demais tratamentos (Figura 2A), o que pode ser explicado pela maior barreira física para romper 0 tegumento das sementes que receberam o revestimento, ocasionando um atraso na germinação. Dados semelhantes foram encontrados por Mendonça et al. (2007), trabalhando com revestimento em sementes de milho doce.

Em relação à germinação (Figura $2 \mathrm{~B}$ ) também se verifica que a testemunha apresentou maior percentual de plântulas normais. Não houve variações acentuadas entre os polímeros estudados até a concentração de $2 \%$, porém, o ALG ocasionou drástica redução na germinação com o aumento das concentrações atingindo o percentual de $35 \%$ de plântulas normais na concentração de $6 \%$. Oliveira et al. (2009) recobrindo sementes de feijão com ALG em uma concentração de $2 \%$ não observaram diminuição na germinação das sementes recobertas em relação à testemunha.

Para a variável IVG observou-se a mesma tendência da PCG e G, em que a testemunha obteve o maior índice e o alginato de sódio apresentou redução acentuada com o aumento das concentrações. O PVOH proporcionou maior IVG, quando comparado aos outros polímeros avaliados (Figura 2C).

Figura 2. Primeira contagem de germinação, germinação, índice de velocidade de germinação e envelhecimento a celerado de sementes de soja cultivar NK 7059RR, sob diferentes concentrações (0, 2, 4 e $6 \%$ ) dos polímeros amido de mandioca (AM), alginato de sódio (ALG) e álcool polivinílico (PVOH).

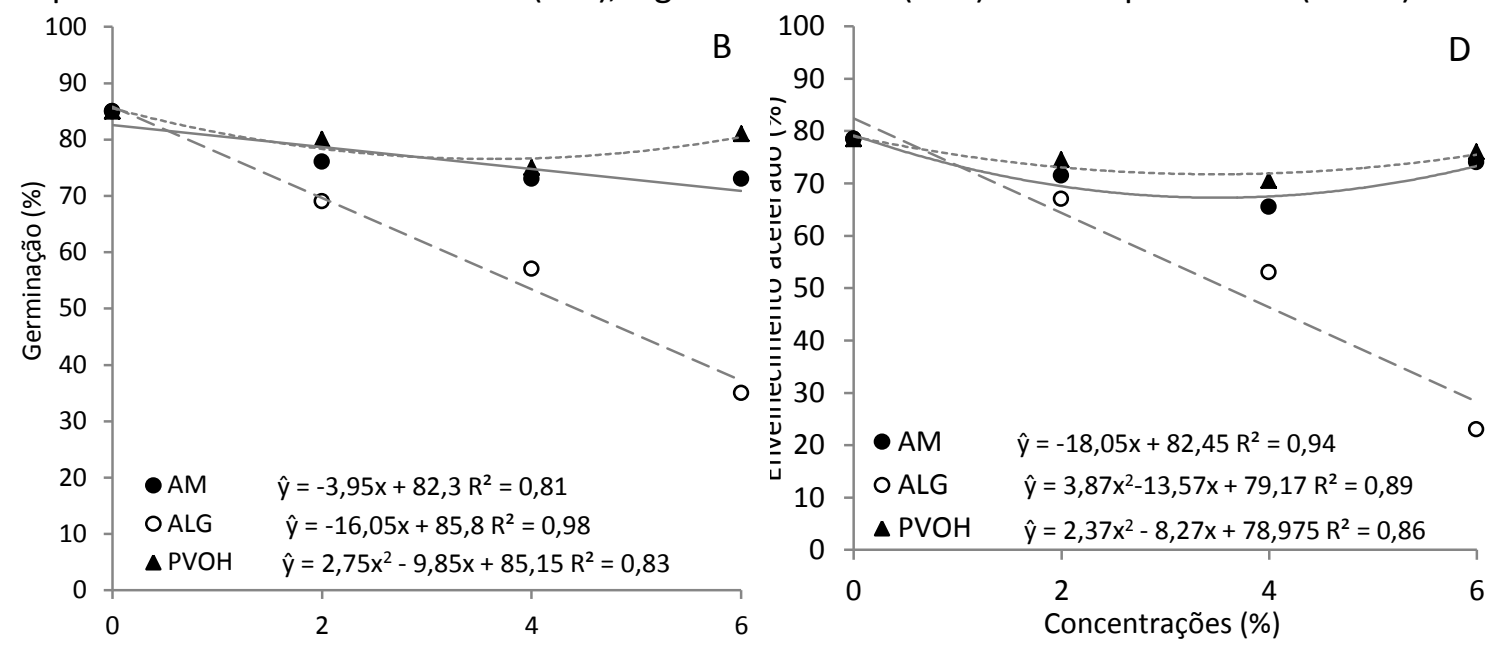

Os polímeros utilizados no presente estudo são hidrofílicos, embora o PVOH possua algumas restrições à hidrofilicidade, assim, quanto maior a concentração dos mesmos, maior tendência à absorção de água ao longo do período de germinação. Analisando os dados da curva de absorção de água (Figura 1) observa-se que houve variações no percentual de água absorvida pela semente dependendo do polímero utilizado e da sua concentração. O ALG implicou em maiores ganhos de água na concentração de $4 \%$ quando comparado aos demais polímeros, podendo ter ocasionado danos por hidratação rápida às sementes. Além disso, todos os polímeros proporcionaram aumentos na absorção de água das sementes com o passar do período de hidratação, sendo que a curva para alginato de sódio na concentração de $6 \%$ apresenta tendência crescente e comportamento superior em relação à absorção de água em relação aos demais polímeros. Este fato pode explicar a redução drástica nas variáveis relacionadas à germinação para este tratamento. Em contrapartida, os revestimentos de AM e $\mathrm{PVOH}$ não implicaram em reduções acentuadas na germinação das sementes, sendo que o PVOH apresentou percentual germinativo de $81 \%$ na maior concentração avaliada, o que está de 
acordo com os padrões de germinação para as sementes de soja exigida pelo MAPA (BRASIL, 2013), provavelmente pela sua limitada hidrofilicidade (KAMOUN et al., 2015).

A aplicação de revestimento às sementes de milho superdoce causou consideráveis reduções na germinação em comparação com as sementes nuas. Houve uma redução significativa da germinação de todas as sementes tratadas independentemente do tipo de material empregado no processo de revestimento (MENDONÇA et al., 2007), corroborando com o presente estudo.

Em relação às variáveis $E A, E C V$ e IVE (Figura 3) observou-se comportamento quadrático para os três polímeros estudados, exceto no EA (Figura $3 A$ ) em que $O$ ALG apresentou redução linear conforme aumentaram as concentrações do polímero, comportamento similar ao observado nas variáveis relacionadas à germinação. As sementes revestidas com AM e $\mathrm{PVOH}$ apresentaram comportamento semelhante para o teste de envelhecimento acelerado. Benatto Junior et al. (2012) avaliando o teste de envelhecimento acelerado em sementes de soja recobertas com polímeros industriais, verificaram que os tratamentos mantiveram valores iguais e/ou maiores que a testemunha, demonstrando um efeito benéfico dos polímeros, protegendo as sementes e garantindo a qualidade fisiológica das mesma.

O comportamento das sementes revestidas quanto à emergência em casa de vegetação (ECV) está apresentada na Figura 3B. As sementes recobertas com o polímero AM foram as que apresentaram maior percentual de plântulas emergidas, seguido das sementes recobertas com o PVOH e ALG, diferentemente dos dados da germinação, onde o PVOH obteve maiores percentagens de plântulas normais germinadas. No solo, a água nem sempre está prontamente disponível à semente. Como o $\mathrm{PVOH}$ é um polímero com menor hidrofilicidade diante dos outros testados, a diferença da emergência em casa de vegetação para a germinação em laboratório pode ser explicada por essa característica do polímero.

Resultados contrários ao presente estudo foram encontrados por Trentini et al. (2005), avaliando o recobrimento de sementes de soja com a película AGL 205. Os autores verificaram valores de germinação de $86 \%$ com a película e $84 \%$ sem a película. Para o envelhecimento acelerado os valores foram de $77 \%$ com a película e $72 \%$ sem a película; emergência em campo $95 \%$ com AGL 205 e 92\% sem a presença desse polímero e IVE $8,92 \%$ com a película e $8,66 \%$ sem a película.

Observando os valores de IVE representado na Figura $2 \mathrm{C}$, verifica-se que as sementes revestidas com amido (AM) emergiram mais rapidamente que os demais polímeros, seguido do ALG e PVOH, que não diferiram entre si.

Figura 3. Emergência em casa de vegetação e Índice de Velocidade de Emergência de sementes de soja cultivar NK 7059RR, sob diferentes concentrações (0, 2, 4 e 6\%) dos polímeros amido de mandioca, alginato de sódio e álcool polivinílico.
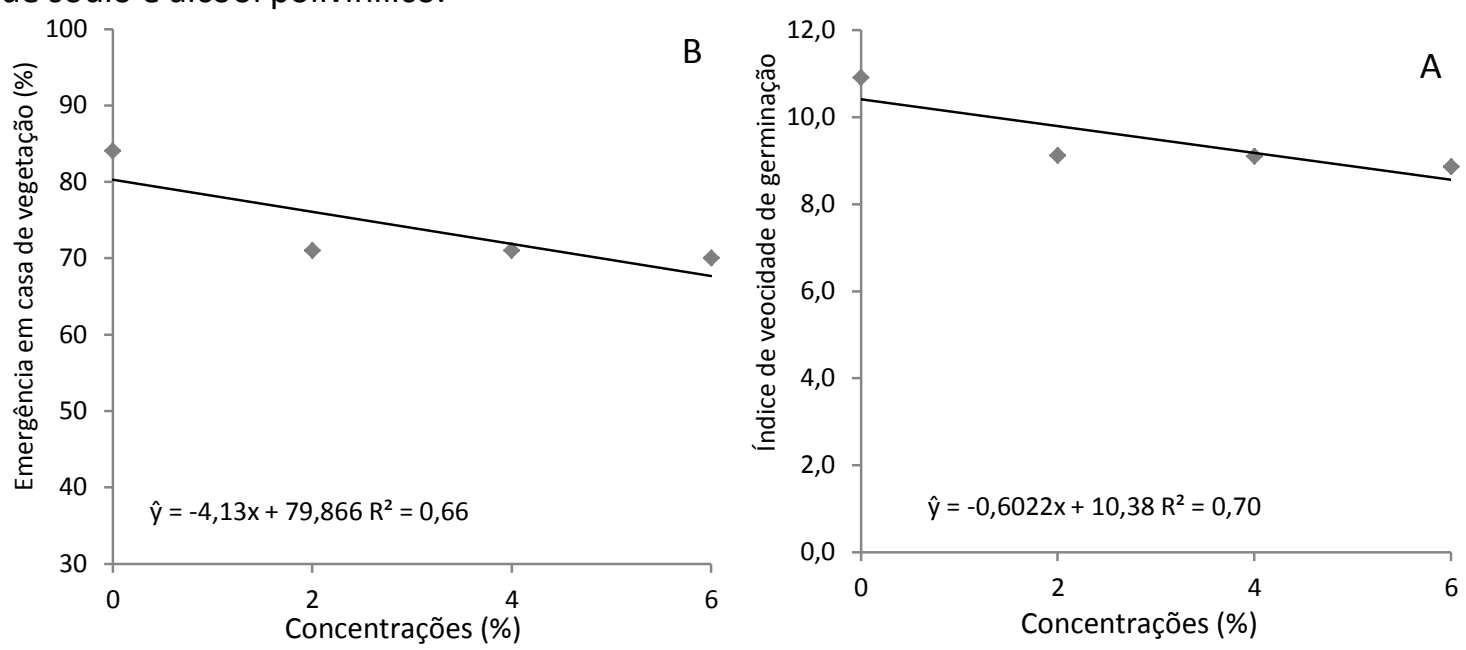
Pode-se observar que a testemunha obteve maior valor para a CE (Figura 4). Isso mostra que os filmes formaram uma barreira entre a semente e a solução de água deionizada do teste, onde lixiviaram menos solutos. De acordo com Pereira et al. (2007) alguns polímeros podem gerar uma barreira impedindo a lixiviação de solutos da semente, promovendo a ela maior vida útil.

Para os polímeros AM e PVOH, observouse pequena diminuição do valor de CE conforme aumentou a concentração dos mesmos. Avaliando doses de polímero de revestimento (hidrofílico) Melo et al. (2014) em sementes de tomate e Evangelista et al. (2007) em sementes de soja não verificaram influência na liberação de solutos durante o teste de condutividade elétrica.
Quando recobertas com o ALG, como o mesmo é muito hidrofílico (LIMA et al., 2007), as sementes expandiam de tamanho devido à rápida absorção de água. Com isso, pode ter ocorrido uma maior desorganização das membranas, aumentando a quantidade de solutos extravasados na solução e assim, o valor da CE. Entretanto, para a concentração de $6 \%$ do ALG a CE foi muito baixa, o que pode ser justificado, conforme já comentado, pela alta viscosidade que esta concentração proporcionou, dificultando a dissolução do polímero e formando uma barreira muito espessa entre a semente e a solução, não permitindo que os solutos das sementes migrassem para a solução, mantendo a CE muito baixa.

Figura 4. Condutividade elétrica (CE) de sementes de soja cultivar NK 7059RR, sob diferentes concentrações $(0,2,4$ e 6\%) dos polímeros amido de mandioca (AM), alginato de sódio (ALG) e álcool polivinílico (PVOH).

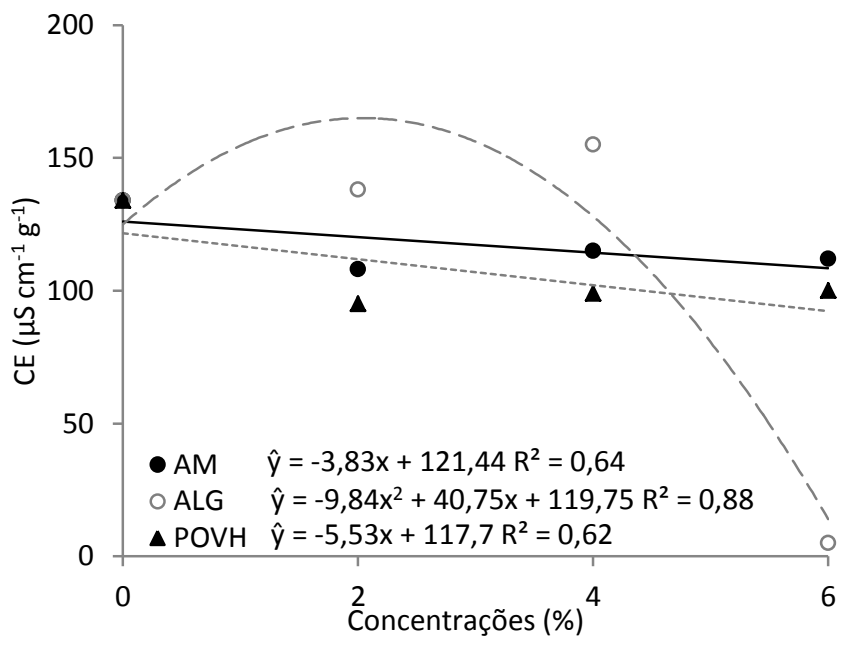

O teste de condutividade elétrica avalia a qualidade das sementes através da determinação da quantidade de lixiviados na solução de embebição das sementes. Os menores valores, correspondentes à menor liberação de exsudatos, indicam alto potencial fisiológico (maior vigor), revelando menor intensidade de desorganização dos sistemas membranas das células (MARCOS FILHO, 2015).

\section{Conclusão}

Os polímeros utilizados no presente estudo aumentam a absorção de água das sementes, principalmente o alginato de sódio na concentração de $4 \%$.

O revestimento com alginato de sódio afeta a qualidade fisiológica das sementes.
O aumento na concentração dos polímeros afeta negativamente a emergência das plântulas, e no caso do alginato de sódio reduz a germinação e o vigor das sementes.

\section{Referências}

BAUDET, L. M.; PERES, W. Seed coating. Seed News, v. 8, p. 20-23, 2004.

BENATTO JUNIOR, J. C.; BARROS, A. C. S. A.; TAVARES, L. C.; RUFINO, C. A.; TUNES, L. V. M.; MENEGHELLO, G. E. Physiological quality of soybeans seeds treated with fungicide and coating with polymers. Revista Brasileira de Ciências Agrárias, v. 7, n. 2, p. 269-273, 2012. https://doi.org/10.5039/agraria.v7i2a1640 
BRANDELERO, R. P. H.; ALMEIDA, F. M de; ALFARO, A. Microestrutura e propriedades de filmes de amido-álcool polivinílico-alginato adicionados de óleos essenciais de copaíba e capim limão. Química Nova, v. 38, n. 7, p. 910916, 2015.

BRASIL. Ministério da Agricultura, Pecuária e Abastecimento. Regras para análise de sementes. Brasília: MAPA/ACS, 2009. 395 p.

BRASIL. Ministério da Agricultura, Pecuária e Abastecimento. Instrução Normativa $\mathrm{n}^{\circ} 45$ Padrões para a produção e a comercialização de sementes de soja. Brasília: MAPA/ACS, 2013.

BRITO, G. F.; AGRAWAL, P.; ARAÚJO, E. M.; MÉLO, T. J. A. Biopolímeros, Polímeros Biodegradáveis e Polímeros Verdes. Revista Eletrônica de Materiais e Processos, v. 6, n. 2, p. 127-139, 2011.

EMPRESA BRASILEIRA DE PESQUISA AGROPECUÁRIA (EMBRAPA). Centro Nacional de Pesquisa de Solos. Sistema brasileiro de classificação de solos. 5. ed. Rio de Janeiro: Embrapa Solos, 2018. 356 p.

EVANGELISTA, J. R. E.; OLIVEIRA, J. A.; BOTELHO, F. J. E.; OlIVEIRA, R. M. E.; PEREIRA, C. E. Desempenho de sementes de soja peliculizadas em solo com diferentes teores de água. Ciência Agrotecnologia, v. 31, n. 4, p. 994-999, 2007.

https://doi.org/10.1590/S1413-

$\underline{70542007000400008}$

FARIAS, S. S. de; SIQUEIRA, S. M. C.; CRISTINO, J. H. S; ROCHA, J. M. da. Biopolímeros: uma alternativa para promoção do desenvolvimento sustentável. Revista Geonorte, v. 7, n. 26, p. 6177, 2016.

FRANÇA NETO, J. B.; HENNING, A. A. Qualidade fisiológica da semente. Londrina: EMBRAPACNPSo., 1984. p. 5-24. (EMBRAPA-CNPSo. Circular Técnica, 9).

FRANÇA NETO, J. B.; KRZYZANOWSKI, F. C.; COSTA, N. P. da. 0 teste de tetrazólio em sementes de soja. Londrina: EMBRAPA-CNPSo, 1998. 72 p. (EMBRAPA-CNPSo. Documentos, 116).
HUTH, C.; CEOLIN, C.; HENNING, L.; M. M.; BARBIERI, A. P. P.; ZEN, H. D.; MATTIONI, N. M.; BACKERS, F. A. A. L. Velocidade de embebição de sementes de soja submetidas a diferentes recobrimentos. Informativo Abrates, v. 23, n. 3, p. 61-64, 2013.

KAMOUN, E. A.; CHEN, X.; ELDIN, M. S. M.; KENAWY, El- R. S. Crosslinked poly (vinyl alcohol) hydrogels for wound dressing applications: a review of remarkably blended polymers. Arabian Journal of Chemistry, v. 8, n. 1, p. 1-14, 2015. https://doi.org/10.1016/i.arabjc.2014.07.005

KRZYZANOWSKI, F. C.; VIEIRA, R. D.; FRANÇA NETO, J. B. (Ed.). Vigor de sementes: conceitos e testes. Brasília: ABRATES, 1999. 218 p.

LIMA, A. M. F.; ANDREANI, L.; SOLDI, V. Influência da adição de plastificante e do processo de reticulação na morfologia, absorção de água e propriedades mecânicas de filmes de alginato de sódio. Química Nova, v. 30, n. 4, p. 832-837, $2007 . \quad$ https://doi.org/10.1590/S0100$\underline{40422007000400014}$

LUDWIG, M. P.; LUCCA FILHO, O. A.; BAUDET, L.; DUTRA, L. M. C.; AVELAR, S. A. G.; CRIZEL, R. L. Qualidade de sementes de soja armazenadas após recobrimento com aminoácido, polímero, fungicida e inseticida. Revista Brasileira de Sementes, v. 33 n. 3, p. 395-406, 2011.

https://doi.org/10.1590/S0101$\underline{31222011000300002}$

MAGUIRE, J. D. Speed of germination-aid in selection and evaluation for seedling emergence and vigor. Crop Science, v. 2, n. 1, p. 176-177, 1962.

https://doi.org/10.2135/cropsci1962.0011183X0 $\underline{00200020033 x}$

MARCOS FILHO, J. Fisiologia de sementes de plantas cultivadas. Londrina: ABRATES, 2015. 659 p.

MARCOS FILHO, J. Teste de Envelhecimento Acelerado. In.: KRZYZANOWSKI, F. C.; VIEIRA, R. D.; FRANÇA NETO, J. B. (Ed.) Vigor de sementes: conceitos e testes. Londrina: ABRATES, 1999. p. 3.1-3.24.

MELO, A. P. C. de; SELEGUINI, A.; VELOSO, V. da R. S.; PEREIRA, J. M. Recobrimento de sementes 
de tomate com concentrações crescentes de polímero sintético. Ciência Rural, v. 45, n. 6, p. 958-963, 2014. https://doi.org/10.1590/0103$\underline{8478 \mathrm{cr} 20131335}$

MENDONÇA, E. A. F. de; CARVALHO, N. M. de; RAMOS, N. P. Revestimento de sementes de milho superdoce $\left(\mathrm{SH}_{2}\right)^{1}$. Revista Brasileira de Sementes, v. 29, n. 2, p. 68-79, 2007.

https://doi.org/10.1590/S0101-

$\underline{31222007000200010}$

OLIVEIRA, A. F. de; SOLDI, V.; COELHO, C. M. M.; MIQUELOTO, A.; COIMBRA, J. L. M. Preparação, caracterização e propriedades de filmes poliméricos com potencial aplicação no recobrimento de sementes. Química Nova, v. 32, n. 7, p. 1845-1849, 2009.

https://doi.org/10.1590/s0100-

$\underline{40422009000700030}$

PEREIRA, C. E.; OLIVEIRA, J. A.; EVANGELISTA, J. R. E.; BOTELHO, F. J. E.; OLIVEIRA, G. E.; TRENTINI, P. Desempenho de sementes de soja tratadas com fungicidas e peliculizadas durante 0 armazenamento. Ciência e Agrotecnologia, v. 31, n. 3, p. 656-665, 2007.

https://doi.org/10.1590/S1413-

$\underline{70542007000300009}$

REDDY, M. M.; VIVEKANANDHAN, S.; MISRA, M.; BHATIA, S. K.; MOHANTY, A. K. Biobased plastics and bionanocomposites: Current status and future opportunities. Progress in Polymer Science, v. 38, n. 10-11, p. 1653-1689, 2013. https://doi.org/10.1016/j.progpolymsci.2013.05. $\underline{006}$

SILVA, F. A. S.; AZEVEDO, C. A. V. Principal components analysis in the software assistatstatistical attendance. In: WORLD CONGRESS ON COMPUTERS IN AGRICULTURE, 7., 2009, Reno. Proceedings [...]. Reno-NVUSA: American Society of Agricultural and Biological Engineers, 2009.

TRENTINI, P.; VIEIRA, M. das G. G. C.; CARVALHO, M. L. M. de; OLIVEIRA, J. A. de; MACHADO, J. C. Peliculização: desempenho de sementes de soja no estabelecimento da cultura em campo na região de Alto Garças, MT. Ciência e Agrotecnologia, v. 29, n. 1, p. 84-92, 2005. https://doi.org/10.1590/S1413$\underline{70542005000100010}$
SYSTAT SOFTWARE. SigmaPlot for windows: version 10.0. San Jose: Systat Software, 2006.

VIEIRA, R. D.; KRZYZANOWSKI, F. C. Teste de condutividade elétrica. In: KRZYZANOWSKI, F. C.; VIEIRA, R. D.; FRANÇA NETO, J. B. (Ed.) Vigor de sementes: conceitos e testes. Londrina: ABRATES, 1999. p. 4.1-4.26.

VIEIRA, R. D.; PENARIOL, A. L.; PERECIN, D.; PANOBIANCO, M. Condutividade elétrica e teor de água inicial das sementes de soja. Pesquisa Agropecuária Brasileira, v. 37, n. 9, p. 1333-1338, $2002 . \quad$ https://doi.org/10.1590/s0100204X2002000900018

WEST, S. H. Polymers as moisture to maitain seed quality. Crop Science, v. 25, n. 6, p. 91-94, 1983. 